\title{
Clinical features, treatment and outcomes in patients with tracheal adenoid cystic carcinoma: a systematic literature review
}

\author{
Juntao $\operatorname{Ran}^{*+}{ }^{*}$, Guofeng Qu ${ }^{*}{ }^{+}$Xiaohua Chen and Da Zhao
}

\begin{abstract}
Background: Primary tracheal adenoid cystic carcinoma (TACC) is rare and originates from the minor salivary gland. Biologically, TACC results in delayed presentation, and the therapeutic effects of multimodal treatment differ across individuals. This study aimed to review cases of TACC to identify clinical features, imaging modalities, treatment, and patient outcomes across follow-ups.

Methods: The PubMed, Web of Science and MEDLINE databases were searched to identify articles reporting cases of TACC. The study variables included in the analysis were patient demographics, biological characteristics, presenting symptoms, imaging modalities, treatments, follow-up times and survival outcomes.

Results: A total of 76 articles and 1252 cases were included in this review. The most common presenting symptom was dyspnoea (86.0\%), followed by cough (58.0\%). Surgery alone (40.9\%), surgery with postoperative radiotherapy (36.4\%) and radiotherapy alone (19.2\%) were used most frequently treatments modalities. Of the 1129 cases with disease control and survival data, there was no evidence of disease in $78.7 \%$, local recurrence was reported in 3.8\%. Distant metastasis rate was $24.9 \%$ of 418 reported cases, lung (44.2\%) was the most commonly involved organ. The 5, 10 years survival rate of patients treated with surgery alone and surgery with postoperative radiotherapy were $86.4 \%$, $55.6 \%$ and $97.3 \%, 44.4 \%$, respectively.

Conclusion: TACC most common presenting symptoms were dyspnoea, cough and shortness of breath. Surgery alone and surgery with postoperative radiotherapy are predominant treatment modalities. Both seems to provide a good result in term of disease control and long-term survival rate in patients with TACC.
\end{abstract}

Keywords: Adenoid cystic carcinoma, Tracheal carcinoma, Systematic review

\section{Introduction}

The incidence of primary tracheal carcinoma is 0.1 to 0.26 per $1,00,000$ persons, accounting for $0.1-0.4 \%$ of all patients with malignant diseases [1-3]. Adenoid cystic carcinoma (ACC) is a rare malignant tumour of the salivary glands and was first described by Billroth in 1856 [4, 5]. Primary tracheal adenoid cystic carcinoma (TACC)

\footnotetext{
*Correspondence: ranjt@|zu.edu.cn; quguofeng2018@163.com †Juntao Ran and Guofeng Qu have contributed equally to this work Department of Radiation Oncology, The First Hospital of Lanzhou University, Lanzhou 730000, People's Republic of China
}

is the second most common tracheal malignant tumour after squamous cell carcinoma [6] and accounts for approximately $10-20 \%$ of all tracheal malignant tumour cases $[5,7,8]$. In terms of its biological characteristics, TACC arises from the submucosal glands, it has an indolent course, it is characterized by a slow growth rate and late distant metastasis $[1,4]$. As a result of the submucosal location of the tumours, the clinical symptoms present late. Patients with this type of tumour commonly present with dyspnoea, cough, wheezing and haemoptysis [9].

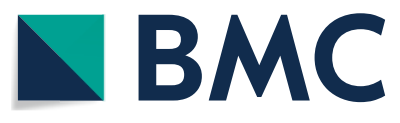

(c) The Author(s) 2021. Open Access This article is licensed under a Creative Commons Attribution 4.0 International License, which permits use, sharing, adaptation, distribution and reproduction in any medium or format, as long as you give appropriate credit to the original author(s) and the source, provide a link to the Creative Commons licence, and indicate if changes were made. The images or other third party material in this article are included in the article's Creative Commons licence, unless indicated otherwise in a credit line to the material. If material is not included in the article's Creative Commons licence and your intended use is not permitted by statutory regulation or exceeds the permitted use, you will need to obtain permission directly from the copyright holder. To view a copy of this licence, visit http://creativecommons.org/licenses/by/4.0/. The Creative Commons Public Domain Dedication waiver (http://creativeco mmons.org/publicdomain/zero/1.0/) applies to the data made available in this article, unless otherwise stated in a credit line to the data. 
Surgical resection is the common modality of treatment for TACC, but complete resection is achieved in only $42-57 \%$ of cases $[6,10,11]$. Adjuvant radiotherapy is generally approved for TACC that were not completely excised [12-14], however, the value of adjuvant radiotherapy for TACC remains controversial according to published literatures. In patients with cases deemed unresectable or contraindications to surgery, definitive radiotherapy is proposed [6]. Only a limited number of cases have been reported, making it difficult to develop protocols based on evidence-based treatment regimens for TACC. Here, we present a systematic review of the reported cases of TACC to identify trends in demographics, presenting symptoms, treatment modalities, and outcomes.

\section{Materials and methods Search strategy}

A comprehensive search of the PubMed, Web of Science and MEDLINE databases was performed to identify articles published up until December 2019, using the terms "tracheal adenoid cystic carcinoma", "tracheal tumours" and "tracheal neoplasm". The results were limited to English-language articles. The title and abstract of studies identified in the search were scanned to exclude any studies that were clearly irrelevant. The full texts of the remaining articles were retrieved and read to determine whether they met the inclusion criteria. The references of the full-text articles were reviewed to identify additional relevant articles. When there was uncertainty about the eligibility of a paper, this was discussed and resolved by consensus within authors.

\section{Selection criteria}

Studies that reported data on the diagnosis and treatment of patients with TACC were included. The exclusion criteria were articles not published in English, histology and radiologic studies, and those on other anatomic locations. Additionally, studies for which the full text could not be obtained and with insufficient data were excluded. Discrepancies among authors on article inclusion were resolved through discussion with other authors. The strength of the evidence of the included articles was assessed with the Oxford Centre for Evidence-Based Medicine classification system.

\section{Data extraction}

Two investigators (J. Ran, G. Qu) reviewed studies and extracted the information on author, publication year, study type, sample size, demographics, presenting symptoms, imaging modalities, treatments, follow-up time, recurrence, and outcomes using a standardized form.
All the analyses were done using Microsoft Excel (2016).

\section{Results}

Literature search

The literature search of PubMed, Web of Science, and MEDLINE identified 874 articles (Fig. 1). Among them, 803 were excluded because they failed to meet the eligibility criteria. Of the remaining 71 articles, the full texts were retrieved and the data analysed. Additionally, 5 articles were retrieved through manual searches of the reference lists. Finally, a total of 26 case series and 50 case reports, 1252 cases, were included in this review (Additional file 1: Table S1), with an aggregate level of evidence of $3 b$.

\section{Demographics and clinical characteristics}

Among all 1252 patients, demographics were reported for 1088 patients, the age but not the sex of 1 patient was reported, and age was not reported for 16 patients. The average patient age was 48.7 years. The gender distribution was skewed towards females with a male to female ratio of 1:1.17. The presenting symptoms were reported for 813 cases, the most common presenting symptom was dyspnoea (86.0\%), followed by cough (58.0\%). The average time between the onset of symptoms and diagnosis was reported for 249 cases and was 12.5 months. The average tumour size was reported for 719 cases and was $3.25 \mathrm{~cm}$. Information regarding treatment modality was available in 1239 patients. The most common primary treatment was surgery alone $(40.9 \%)$ and surgery with adjuvant radiotherapy (36.4\%). The average and median doses of adjuvant radiotherapy were 55.8 Gy and 54 Gy (Range: 40 Gy-77 Gy). The average and median doses of radical radiotherapy were 63.9 Gy and 60 Gy (Range: 46 Gy-80 Gy). One patient underwent stent implantation and one patient receive no treatment. Clinical characteristics are summarized in Table 1.

\section{Radiography and endoscopy}

The radiographic imaging modalities reported of 949 patients are listed in Table 1. The following imaging modalities were used alone or in combination with other techniques: computed tomography (CT), bronchoscopy, laryngoscopy, MRI, PET-CT and X-ray. The most commonly used radiographic imaging modalities were $\mathrm{CT}$ with bronchoscopy.

\section{Survival outcomes}

The 1129 cases for which the follow-up time and outcome measures were available, the average followup time was 49.8 months, with a range from 1 to 162 months, there were no evidence of disease in 889 


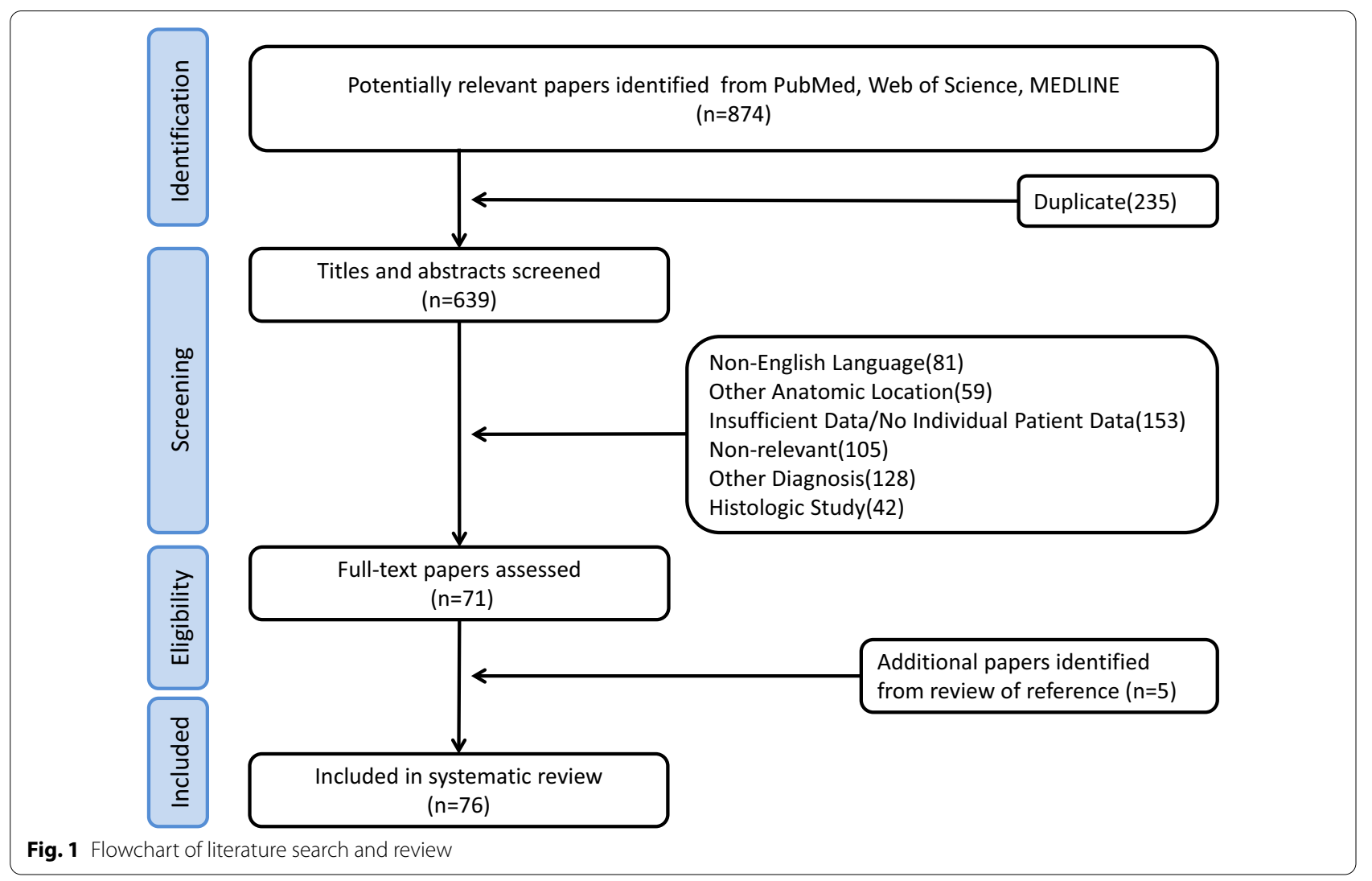

cases $(78.7 \%)$ and local recurrence in 43 cases (3.8\%). Of 418 reported cases with regional and distant metastasis data, lymph node metastasis was reported in 93 cases $(22.2 \%)$, and distant metastasis in 104 cases (24.9\%), and the lung $(46 / 104,44.2 \%)$ was the most commonly involved organ.

Survival outcomes of the different treatment modality are displayed in Table 2. At the time of this analysis, outcomes of 239 cases treated with surgery alone were available, the follow-up time was 119.4 months, $86.4 \%$ $(184 / 213)$ of the patient were alive at 5 years, $55.6 \%$ $(90 / 162)$ of the patients were alive at 10 years. The follow-up duration was available for 189 cases treated with surgery and postoperative radiotherapy and was 77.3 months, the 5 years and 10 years survival rate were $97.3 \%$ and $44.4 \%$ of 189 cases, respectively. The followup time of 58 cases treated with radiotherapy alone was 45.4 months, the 5 years and 10 years survival rate were $34.9 \%$ and $16.1 \%$ of 43 cases, respectively. Twenty-six cases were treated by surgery, radiotherapy and chemotherapy, the 5 years survival rate was $88.9 \%$ of 9 cases, and the follow-up time for 12 cases was 94.4 months.

\section{Discussion}

Most of the information about TACC is derived from case reports and short series due to the rarity of the disease, which is often restricted by limited information about treatment and survival. The present systematic review aimed to provide more comprehensive information on clinical features, patterns of treatments and survival outcomes of TACC.

The present analysis showed that the average age of the entire cohort was 48.7 years, this is comparable with literature results $[10,14-16]$. Earlier studies $[3,10,17]$ reported there were no significant difference between the frequency of male and female patients, which is consistent with the finding of the present analysis. Besides, our review found that the interval between the onset of symptoms and diagnosis was 12.5 months, which is similar to that reported in the majority of case series and differs from that reported in the case reports $[10,18-20]$. The relatively long time may relate to the indolent clinical behaviour and non-specific sign of TACC. Furthermore, this study indicated that the most common symptom of TACC was dyspnoea, followed 
Table 1 Patient clinical characteristics and treatments

\begin{tabular}{ll}
\hline Patient characteristics & $\mathbf{n}(\%)$ \\
\hline All patients & 1252 \\
Demographics & 1088 \\
Average age (years) & $48.7(14-97)$ \\
Gender & \\
Male & 501 \\
Female & 587 \\
Presenting symptoms & 813 \\
Dyspnea & $699(86.0)$ \\
Cough & $471(58.0)$ \\
Shortness of breath & $302(37.1)$ \\
Hemoptysis & $125(15.4)$ \\
Wheeze & $32(3.9)$ \\
Pectoralgia & $20(2.5)$ \\
Stridor & $7(0.9)$ \\
Neck swelling & $3(0.4)$ \\
Hoarseness & $2(0.2)$ \\
Radiography, Endoscopy & 949 \\
CT and Bronchoscopy & $687(72.4)$ \\
Bronchoscopy & $162(17.1)$ \\
CT or PET-CT & $72(7.6)$ \\
X-ray and Bronchoscopy & $22(2.3)$ \\
CT and larynoscopy & $4(0.4)$ \\
MRl and/or larynoscopy & $2(0.2)$ \\
Treatment modalities & 1239 \\
Surgery & $507(40.9)$ \\
Surgery and RT & $451(36.4)$ \\
RT & $238(19.2)$ \\
Surgery, RT and Chemotherapy & $26(2.1)$ \\
Surgery and Chemotherapy & $10(0.8)$ \\
RT and Chemotherapy & $4(0.03)$ \\
Chemotherapy & $1(0.01)$ \\
Other & $2(0.02)$ \\
\hline
\end{tabular}

by cough. However, a variety of other symptoms were reported, including haemoptysis, wheezing, pectoralgia, stridor, neck swelling, and hoarseness [7, 21-24].
The discrepancy among reports may be due to the small sample sizes of most studies.

The pre-treatment imaging modality used commonly in the evaluation of TACC was CT and bronchoscopy [18, 25]. In addition, MRI, PET-CT, X-ray and laryngoscopy were also used for examinations [22, 26-28]. According to our assessment of radiologic modality, the most common modalities performed to establish the diagnosis and assess the condition of the disease were also $\mathrm{CT}$ and Bronchoscopy. CT imaging can be used to determine the tumour location, extension, regional invasion and lung metastasis, and provide important information for treatment options. Bronchoscopy reveals the location and growth of the tumour, and biopsy can be performed for a pathological diagnosis. MRI and PET-CT were adopted in relatively little cases, the manifestation and value of them in diagnosis of TACC need to further evaluate. But PET-CT may have a role for residual tumour and target delineation of radiotherapy.

It is wildly accepted that radical surgical resection is associated with better survival outcomes in TACC. Studies have reported that the 5-year survival rate was $88 \%-100 \%$, the 10 -year survival rate was $51 \%-80 \%$ with surgery alone $[14,17,18,29]$. These results are comparable with the survival rate in this review (5-year survival rate $86.4 \%$; 10 -year survival rate $55.6 \%$ ). However, given the limited scope of tracheal resection and the tendency for TACC to spread in submucosal tissue, the complete resection is not always achievable, the positive rate of resection margin is 59-63\%. In addition, the extent of excision can increase the surgical complication and operative mortality rates [21]. Some studies reported that the mortality rate related to surgical procedures was $1 \%-25 \%[14,21,22,30]$. Hence, postoperative radiotherapy is usually recommended for TACC with non-R0 resection. Surgical margin status and palliative resection were identified to be associated with receiving adjuvant radiotherapy in routine clinical practice, and it can increase the survival rate and decrease the risk of local recurrence and distant metastasis [16, 31-33]. But the inclusion of radiotherapy in the treatment of TACC remain controversial because of

Table 2 Outcomes stratified by the treatment modality used for tracheal adenoid cystic carcinoma

\begin{tabular}{|c|c|c|c|c|c|c|c|}
\hline \multirow[t]{2}{*}{ Treatment modality } & \multirow{2}{*}{$\begin{array}{l}\text { Number } \\
\text { of cases }\end{array}$} & \multirow{2}{*}{$\begin{array}{l}\text { Follow-up } \\
\text { cases }\end{array}$} & \multirow{2}{*}{$\begin{array}{l}\text { Follow-up } \\
\text { time }(\mathrm{m})\end{array}$} & \multicolumn{2}{|l|}{5 years } & \multicolumn{2}{|l|}{10 years } \\
\hline & & & & $\begin{array}{l}\text { Follow-up } \\
\text { cases }\end{array}$ & survival rate, $\%$ & $\begin{array}{l}\text { Follow-up } \\
\text { cases }\end{array}$ & survival rate, $\%$ \\
\hline Surgery alone & 507 & 239 & 119.4 & 213 & 86.4 & 162 & 55.6 \\
\hline Surgery and RT & 451 & 189 & 77.3 & 189 & 97.3 & 189 & 44.4 \\
\hline RT alone & 238 & 58 & 45.4 & 43 & 34.9 & 43 & 16.1 \\
\hline Surgery, RT and CT & 26 & 12 & 94.4 & 9 & 88.9 & - & - \\
\hline
\end{tabular}

$R T$ radiotherapy, $C T$ chemotherapy 
no trials exploring the role of postoperative radiotherapy $[2,14,30,34,35]$. In the review, surgery and postoperative radiotherapy was used in $36.4 \%$ of patients, and the 5-year survival rate was $97.3 \%$, the 10 -year survival rate was $44.4 \%$. This clearly supports the role of postoperative radiotherapy in TACC.

For unresectable disease, definitive radiotherapy is generally employed. Nevertheless, very little reports have been indicated on nonsurgical therapeutic alternatives. In our review, $34.9 \%$ patient lived more than 5 years, $16.1 \%$ more than 10 years after radiotherapy alone. Although this survival rate is inferior to surgery alone and postoperative radiotherapy, it is obviously that radiotherapy is a good therapeutic alternative for unresectable TACC. Furthermore, Högerle et al. [29] reported that the curative effect of definitive radiotherapy is similar to that of surgery with radiotherapy.

Several limitations should be considered when interpreting these results. First, the quality of all the included publications represents primary limitation in the review. The studies did not uniformly report variables of observational indexes and information regarding symptoms, tumour size, imaging modalities, treatment modalities and survival rate was incomplete in most reports. Due to the heterogeneity of the studies and the different follow-up times of the subgroups, the analysis is susceptible to bias. Second, according to the Oxford Centre for Evidence-based Medicine, the majority of studies included in this review had evidence levels of 3 and 4, indicating poor levels of evidence. But being a rare tumour very little data is available, it is difficult to get good quality data and a randomized controlled trial is very difficult to conduct. Finally, the studies in this systematic review were published from 1969 to 2019, the management of technology and treatment is not homogeneous and may influence outcome results during this time. Hence, our results may underestimate benefit of modern technology of surgery and radiotherapy. However, though not conclusive, our finding will provide directions to physicians to make treatment decisions till better quality data comes up.

\section{Conclusion}

TACC commonly presents with dyspnoea and cough. The main examination modalities were $\mathrm{CT}$ and bronchoscopy. Treatment of TACC is challenging, surgery alone and surgery followed by postoperative radiotherapy were the most performed treatment modalities, and the long-term survival rate was high in the majority of patients at the follow-up. In patients presenting with an unresectable/inoperable tumour, definitive radiotherapy is recommended as appropriate therapy.

\section{Supplementary Information}

The online version contains supplementary material available at https://doi. org/10.1186/s13014-021-01770-0.

Additional file 1. Studies meeting criteria for the systematic review.

\section{Abbreviations}

ACC: Adenoid cystic carcinoma; RT: Radiotherapy; CT: Chemotherapy; BS: Bronchoscopy; LS: Larynoscopy; OS: Overall survive.

\section{Acknowledgements}

Not applicable.

\section{Authors' contributions}

J.Ran and G.Qu were responsible for conception, research goals and aims. J Ran, G Qu and X Chen contributed to design of methodology, writing of the protocol, data analysis and interpretation. All authors read and approved the final manuscript.

\section{Funding}

This work is supported by the Health Research Management Project of Gansu Province (GSWSKY-2019-79), and the Key Research and Development Program of Gansu Province (20YF3FA028).

\section{Availability of data and materials}

All data generated or analysed during this study are included in this published article.

\section{Ethics approval and consent to participate}

Not applicable.

\section{Consent for publication}

Not applicable.

\section{Competing interests}

The authors declare no conflict of interest.

Received: 17 December 2020 Accepted: 11 February 2021

Published online: 19 February 2021

\section{References}

1. Santhosh Kumar N, lype EM, Thomas S, Sankar UV. Adenoid cystic carcinoma of the trachea. Indian J Surg Oncol. 2016;7:62-6.

2. Agrawal S, Jackson C, Celie KB, Dodhia C, Monie D, Monzon J, et al. Survival trends in patients with tracheal carcinoma from 1973 to 2011. Am J Otolaryngol. 2017;38:673-7.

3. Honings J, van Dijck JA, Verhagen AF, et al. Incidence and treatment of tracheal cancer: a nationwide study in the Netherlands. Ann Surg Oncol. 2007; 14:968-76.

4. Marchiano E, Chin OY, Fang CH, Park RH, Baredes S, Eloy JA. Laryngeal adenoid cystic carcinoma. Otolaryngology-Head and Neck Surgery. 2015;154:433-9.

5. Ning Y, He W, Bian DL, Xie D, Jiang GN. Tracheo-bronchial adenoid cystic carcinoma: a retrospective study. Asia Pac J Clin Oncol. 2019;15:244-9.

6. Levy A, Omeiri A, Fadel E, Le Pechoux C. Radiotherapy for tracheal-bronchial cystic adenoid carcinomas. Clin Oncol (R Coll Radiol). 2018;30:39-46.

7. Huo Z, Wu H, Li S, Liang Z. Molecular genetic studies on EGFR, KRAS, BRAF, ALK, PIK3CA, PDGFRA, and DDR2 in primary pulmonary adenoid cystic carcinoma. Diagn Pathol. 2015;10:161.

8. Chan WL, Lee VHF, Siu SWK, Leung TW. Inoperable adenoid cystic carcinoma of Trachea: complete remission after multi-modality treatment. Hong Kong J Radiol 2014:203-207.

9. Calzada AP, Miller M, Lai CK, Elashoff DA, Abemayor E, John MAS. Adenoid cystic carcinoma of the airway: a 30-year review at one institution. Am J Otolaryngol. 2012;33:226-31. 
10. Gaissert HA, Grillo HC, Shadmehr MB, Wright CD, Gokhale M, Wain JC, et al. Long-term survival after resection of primary adenoid cystic and squamous cell carcinoma of the trachea and carina. Ann Thoracic Surg. 2004;78:1889-97.

11. Kanematsu T, Yohena T, Uehara T, Ushijima C, Asoh H, Yoshino I, et al. Treatment outcome of resected and nonresected primary adenoid cystic carcinoma of the lung. Ann Thorac Cardiovasc Surg. 2002;8:74-7.

12. Chen F, Huang M, Xu Y, Li T, Xie K, Zhang L, et al. Primary tracheal adenoid cystic carcinoma: adjuvant treatment outcome. Int J Clin Oncol. 2015;20:686-92

13. Shadmehr MB, Farzanegan $R$, Graili P, Javaherzadeh M, Arab M, Pejhan $\mathrm{S}$, et al. Primary major airway tumors; management and results. Eur J Cardiothorac Surg. 2011;39:749-54.

14. Yang H, Yao F, Tantai J, Zhao Y, Tan Q, Zhao H. Resected tracheal adenoid cystic carcinoma: improvements in outcome at a single institution. Ann Thoracic Surg. 2016;101:294-300.

15. Hsu AA, Tan EH, Takano AM. Lower respiratory tract adenoid cystic carcinoma: its management in the past decades. Clin Oncol (R Coll Radiol). 2015;27:732-40.

16. Je HU, Song SY, Kim DK, Kim YH, Jeong SY, Back GM, et al. A 10-year clinical outcome of radiotherapy as an adjuvant or definitive treatment for primary tracheal adenoid cystic carcinoma. Radiation Oncology. 2017;12(1):196.

17. Zhao Y, Zhao H, Fan L, Shi J. Adenoid cystic carcinoma in the bronchus behaves more aggressively than its tracheal counterpart. Ann Thorac Surg. 2013;96:1998-2004.

18. Wo Y, Li S, Wang Y, Lu T, Qin Y, Sun $X$, et al. Predictors of nodal metastasis and prognostic significance of lymph node ratio and total lymph node count in tracheobronchial adenoid cystic carcinoma. Cancer Manag Res. 2018;10:5919-25.

19. Zunker HO, Moore RL, Baker DC, Lattes R. Adenoid cystic carcinoma (cylindroma) of the trachea: case report with 9-year follow-up. Cancer. 1969;23:699-707.

20. Masih I, Porter G, Porter S, Clarke R, Sidhu P, Harney J, et al. Primary adenoid cystic carcinoma of the bronchus in a female teenager. BMJ Case Rep 2010; 8:1-4.

21. Maziak DE. Biology of adenoid cystic carcinoma of the tracheobronchial tree and principles of management. Thoracic Surg Clin. 2018;28:145-8.

22. Pearson FG, Thompson DW, Weissberg D, Simpson WJ, Kergin FG. Adenoid cystic carcinoma of the trachea. Experience with 16 patients managed by tracheal resection. Ann Thorac Surg 1974; 18:16-29.

23. Wright CL, Gandhi M, Mitchell CA. Adenoid cystic carcinoma of the left main bronchus mimicking MacLeod's syndrome. Thorax. 1996;51:451-2.

24. Nuwal $P$, Dixit $R$, Singhal AK. Primary adenoid cystic carcinoma of trachea presenting as midline neck swelling and mimicking thyroid tumor: a case report and review of literature. Lung India. 2010;27:167-9.
25. Honings J, Gaissert HA, Weinberg AC, Mark EJ, Wright CD, Wain JC, et al. Prognostic value of pathologic characteristics and resection margins in tracheal adenoid cystic carcinoma. Eur J Cardiothorac Surg. 2010;37:1438-44.

26. Sweeney L, Vernimmen F, Sinske S. MRI of a recurrent adenoid cystic carcinoma of the trachea, treated with fast neutron therapy. BJR Case Rep. 2016;2:20150201.

27. Baydur A, Gottlieb L. Adenoid cystic carcinoma (Cylindroma) of the Trachea Masquerading as Asthma. JAMA. 1975;234:829-31.

28. Archuna U. Adenoid cystic carcinoma of the trachea: a case report. Med J Malaysia. 2000;55:273-6.

29. Högerle BA, Lasitschka F, Muley T, Bougatf N, Herfarth K, Adeberg S, et al. Primary adenoid cystic carcinoma of the trachea: clinical outcome of 38 patients after interdisciplinary treatment in a single institution. Radiat Oncol. 2019;14(117):1-9.

30. Regnard JF, Fourquier P, Levasseur P. Results and prognostic factors in resections of primary tracheal tumors: a multicenter retrospective study. The French Society of Cardiovascular Surgery. J Thorac Cardiovasc Surg. 1996; 111:808-813.

31. Jeffrey Yang CF, Shah SA, Ramakrishnan D, Raman V, Diao K, Wang H, et al. Impact of positive margins and radiation after tracheal adenoid cystic carcinoma resection on survival. Ann Thorac Surg. 2020;109:1026-32.

32. Webb BD, Walsh GL, Roberts DB, Sturgis EM. Primary tracheal malignant neoplasms: The University of Texas MD Anderson Cancer Center experience. J Am Coll Surg. 2006;202:237-346.

33. Alongi F, Di Muzio N, Motta M, Broggi S, De Martin E, Bolognesi A, Cattaneo M, Calandrino R, Fazio F. Adenoid cystic carcinoma of trachea treated with adjuvant hypofractionated tomotherapy. Case report and literature review. Tumori. 2008;94(1):121-5.

34. Prommegger R, Salzer GM. Long-term results of surgery for adenoid cystic carcinoma of the trachea and bronchi. Eur J Surg Oncol. 1998;24:440-4.

35. Yusuf M, Gaskins J, Trawick E, Tennant P, Bumpous J, Berkel V, et al. Effects of adjuvant radiation therapy on survival for patients with resected primary tracheal carcinoma: an analysis of the national cancer database. Jpn J Clin Oncol,2019:1-12.

\section{Publisher's Note}

Springer Nature remains neutral with regard to jurisdictional claims in published maps and institutional affiliations.

Ready to submit your research? Choose BMC and benefit from:

- fast, convenient online submission

- thorough peer review by experienced researchers in your field

- rapid publication on acceptance

- support for research data, including large and complex data types

- gold Open Access which fosters wider collaboration and increased citations

- maximum visibility for your research: over $100 \mathrm{M}$ website views per year

At BMC, research is always in progress.

Learn more biomedcentral.com/submissions 